\title{
MISCELLANEOUS NEW NAMES AND COMBINATIONS IN SCROPHULARIACEAE - MANULEAE
}

\author{
O.M. HILLIARD
}

\begin{abstract}
Manulea derustiana is newly described, and a ditypic genus, Reyemia, is described with a new species, $R$. chasmanthiflora, as its type, and Zaluzianskya nemesioides is transferred to it.
\end{abstract}

Manulea derustiana Hilliard, species nova a $M$. latiloba Hilliard calycis lobis longioribus et proportione angustioribus (anticis $2.5-3 \times 0.8 \mathrm{~mm}$, nec $1.5-2 \times 0.6-1 \mathrm{~mm}$ ), dorso marginibusque pilis sphaerocephalis dispersis usque ad $0.25 \mathrm{~mm}$ longis (nec pilis sphaerocephalis sparsis \pm sessilibus) praeditis, corollae tubo c.4mm longo (nec 2$2.5 \mathrm{~mm}$ ) differt.

Type: Cape, Oudtshoorn distr., 3322 CB, De Rust, north of Le Roux station, $1800 \mathrm{ft}, 5$ viii 1990, Viviers \& Vlok 479 (holo. E, iso. K, NBG, S).

Reyemia Hilliard, genus novum a Zaluzianskya F.W. Schmidt floribus distincte pedicellatis et laxe paniculatis (nec floribus sessilibus vel subsessilibus in racemos terminales dispositis), corollae limbo resupinato, pilis clavatis in postico faucis latere (nec fauce glabro etsi ore saepe pilis circumcincto), staminibus 2 et staminodiis 2 (nec staminibus 4 vel 2, staminodiis absentibus) differt. A Phyllopodio Benth. forma corollae et limbo corollae resupinato (labio antico integro, labio postico 4-lobato, nec lobo antico 3-lobed, limbo postico bilobato, staminibus 2 posticis fertilibus et staminodiis 2 (nec staminibus plerumque 4 fertilibus sed specie unica Phyllopodii staminibus posticis abortis), filamentis ad basin corollae tubi decurrentibus (nec breviter decurrentibus tantum) differt.

Type species: Reyemia chasmanthiflora Hilliard.

The generic name commemorates Dr H Meyer, who practised medicine in Calvinia in the $1860 \mathrm{~s}$ and whose collections from the Hantam Mountains are the basis of many names, including $R$. nemesioides.

Reyemia chasmanthiflora Hilliard, species nova a $R$. nemesioide (Diels) Hilliard corollae tubo multo longiore (c. $27-30 \mathrm{~mm}$ longo, nec $7-8.5 \mathrm{~mm}$ ) et lobis angustioribus (lobo antico $7.5 \times 1.5 \mathrm{~mm}$, nec $3.5-6 \times 3.6 \times 5 \mathrm{~mm}$, lobis posticis c. $7 \times 2.2 \mathrm{~mm}$, nec $3.5 \times$ $3 \mathrm{~mm}$ ) facile distinguitur.

Type: Cape, Calvinia div., 3120 CB, farm Annexe Kransfontein 721, 1123m, 2 ix 1986, Cloete \& Haselau 172 (holo. STE).

Reyemia nemesioides (Diels) Hilliard, comb. nov.

Type: Cape, Calvinia div., Hantam Mountains, Meyer s.n. (holo. B $\dagger$ ).

Syn.: Zaluzianskya nemesioides Diels in Bot. Jahrb. 23: 482 (1896). 